\title{
Shikimic Acid Promotes Oligodendrocyte Precursor Cell Differentiation and Accelerates Remyelination in Mice
}

\author{
Fengfeng $\mathrm{Lu}^{1,2} \cdot$ Dou Yin ${ }^{1,2} \cdot$ Yingyan $\mathrm{Pu}^{2} \cdot$ Weili Liu ${ }^{1,2} \cdot$ Zhenghao $\mathrm{Li}^{2} \cdot$ \\ Qi Shao ${ }^{2} \cdot$ Cheng $\mathrm{He}^{1,2} \cdot \mathrm{Li} \mathrm{Cao}^{2}$
}

Received: 28 May 2018/ Accepted: 27 September 2018/Published online: 25 January 2019

(C) The Author(s) 2019

\begin{abstract}
The obstacle to successful remyelination in demyelinating diseases, such as multiple sclerosis, mainly lies in the inability of oligodendrocyte precursor cells (OPCs) to differentiate, since OPCs and oligodendrocytelineage cells that are unable to fully differentiate are found in the areas of demyelination. Thus, promoting the differentiation of OPCs is vital for the treatment of demyelinating diseases. Shikimic acid (SA) is mainly derived from star anise, and is reported to have antiinfluenza, anti-oxidation, and anti-tumor effects. In the present study, we found that SA significantly promoted the differentiation of cultured rat OPCs without affecting their proliferation and apoptosis. In mice, SA exerted therapeutic effects on experimental autoimmune encephalomyelitis (EAE), such as alleviating clinical EAE scores, inhibiting inflammation, and reducing demyelination in the CNS. SA also promoted the differentiation of OPCs as well as their remyelination after lysolecithin-induced demyelination. Furthermore, we showed that the promotion effect of SA on OPC differentiation was associated with the up-regulation of phosphorylated mTOR. Taken together, our results
\end{abstract}

Fengfeng Lu, Dou Yin and Yingyan Pu have contributed equally to this work.

\footnotetext{
Cheng $\mathrm{He}$

chenghe@smmu.edu.cn

$\triangle \mathrm{Li} \mathrm{Cao}$

caoli@smmu.edu.cn

1 Institute of Physical Science and Information Technology, Anhui University, Hefei 230601, China

2 Institute of Neuroscience, Key Laboratory of Molecular Neurobiology of The Ministry of Education, and The Collaborative Innovation Center for Brain Science, Second Military Medical University, Shanghai 200433, China
}

demonstrated that SA could act as a potential drug candidate for the treatment of demyelinating diseases.

Keywords Shikimic acid - Oligodendrocyte precursor cells $\cdot$ Demyelination $\cdot$ Remyelination

\section{Introduction}

Oligodendrocyte precursor cells (OPCs) are widely distributed in the adult central nervous system (CNS). They originate from neural stem cells that line ventricles in discrete regions throughout the brain and spinal cord during embryonic development, then proliferate and migrate through the white matter, and finally differentiate into myelinating oligodendrocytes (OLs) after birth [1]. Mature OLs wrap axons in layers to form the myelin sheath that protects axons, facilitates the rapid conduction of action potentials, and electrically insulates fibers from one another [2, 3]. Damage to OLs caused by ischemia, hypoxia, or inflammation can lead to demyelination, which not only influences the transmission of neural signals, but also results in irreversible axonal degeneration. In most cases, OPCs rapidly cluster at lesions after demyelination to proliferate and differentiate into mature OLs, form new myelin sheaths, and wrap exposed axons to achieve functional restoration [4]. However, remyelination only occurs at an early stage but fails at later stages in many demyelinating diseases such as multiple sclerosis (MS) [3, 5]. Such a failure of remyelination is mainly attributable to the inability of OPCs to differentiate and mature in demyelinating lesions [6]. Therefore, promoting the differentiation and maturation of OPCs is crucial to the treatment of these demyelinating diseases. 
Shikimic acid (SA), a hydrogenated metabolite of the shikimate pathway, is a precursor for the synthesis of aromatic compounds such as cinnamic acid, flavonoids, alkaloids, anthocyanins, indoles, flavones, alcohol and tannins in plants and microorganisms [7-9]. It is also known as the primary base material for the synthesis of the neuraminidase inhibitor Oseltamivir (Tamiflu $\left.{ }^{\circledR}\right)$, which is commonly used to treat the $\mathrm{H} 5 \mathrm{~N} 1$ and $\mathrm{A} / \mathrm{H} 1 \mathrm{~N} 1$ strains of influenza [10]. Apart from that, researchers have also found that it has anti-cancer effects [11]. Administration of SA at $200 \mathrm{mg} / \mathrm{kg}$ can decrease the expression of pro-inflammatory cytokines induced by lipopolysaccharide and reduce mechanical hyperalgesia in mice [12]. In addition, SA and its derivative, 3,4-oxo-isopropylidene-shikimic acid, can inhibit platelet aggregation and arterial, venous and cerebral thrombosis as well as promote recovery from ischemic injury $[13,14]$. However, the effects of SA on CNS demyelinating diseases are not clear. In this study, we demonstrated that SA can promote the differentiation and maturation of OPCs and accelerate remyelination, suggesting a potential application in the clinical treatment of demyelinating diseases.

\section{Materials and Methods}

\section{Animals and Shikimic Acid}

C57BL/6 J mice were purchased from Shanghai SLAC Laboratory Animal Co., Ltd (Shanghai, China), maintained under specific pathogen-free conditions, and used at 6 weeks- 8 weeks of age. All animal experiments were performed in adherence with the National Institutes of Health Guidelines on the Use of Laboratory Animals and approved by the Second Military Medical University Committee on Animal Care.

SA was from Sigma-Aldrich (St. Louis, MO), rapidly dissolved in phosphate-buffered saline (PBS) at $100 \mathrm{mg} /$ $\mathrm{mL}$ as stock solution $(100 \times)$, and stored in the dark at $4^{\circ} \mathrm{C}$. SA was freshly prepared before use.

\section{$L$ - $\alpha$-lysophosphatidylcholine (LPC) Induced Focal Demyelination in the Dorsal Spinal Cord}

Adult ( 8 weeks-10 weeks old) female C57BL/6 mice were anesthetized by intraperitoneal injection of $3.6 \%$ chloral hydrate, and kept on an electric heating pad during the manipulative procedure. Focal demyelination in dorsal spinal cord was induced by LPC (62962, Sigma-Aldrich) as described previously $[15,16]$. Briefly, $1 \mu \mathrm{L}$ of LPC $(0.1 \%$ in saline) was injected into the dorsal column at the T11T12 vertebrae with a micromanipulator. Three days after injection, SA and vehicle were intraperitoneally administered. Mice were anesthetized and sacrificed at 7 days and 14 days after LPC injection, then the spinal cord containing the injection lesion was collected and cut into serial paraffin sections. The demyelinated lesion volume was calculated based on the equation: $V=\sum$ demyelinated lesion area $\times$ thickness of section [17].

\section{Experimental Autoimmune Encephalomyelitis (EAE) Model}

The EAE model was induced with myelin oligodendrocyte glycoprotein $\left(\mathrm{MOG}_{35-55}\right)$ as previously described [18]. Briefly, female C57BL/6 mice (7 weeks-8 weeks old) were subcutaneously injected with $200 \mu \mathrm{L}$ of emulsified liquid (mixing ratio, 1:1) consisting of $\mathrm{MOG}_{35-55}$ (GL Biochem, Shanghai, China) dissolved in $1 \times \mathrm{PBS}$ at $1 \mathrm{mg} /$ $\mathrm{mL}$ and heat-killed Mycobacterium tuberculosis (H37Ra strain, Difco, Detroit, MI) mixed evenly in incomplete Freund's adjuvant (Sigma-Aldrich) at $5 \mathrm{mg} / \mathrm{mL}$. Injections were made at 3 points on the back. The day of injection was recorded as 0 day post-injection (dpi). Pertussis toxin $(100 \times) \quad(516561$, Calbiochem-EMD Chemicals, San Diego, CA) was dissolved in $1 \times$ PBS and administered intraperitoneally at $0 \mathrm{dpi}$ and $2 \mathrm{dpi}$. SA was injected intraperitoneally at 15 dpi. Clinical EAE scores were graded daily in a blind manner as follows: 0 , no observable symptoms; 1, limp tail; 2, limp tail and partial limb weakness; 3 , one hindlimb paralyzed; 4 , both hindlimbs paralyzed; 5 , moribund or dead.

\section{Primary Oligodendrocyte Progenitor Cell Culture}

OPCs were cultured and purified as described previously $[19,20]$. Briefly, mixed glial cells were harvested from P0 rat cortex and cultured in Dulbecco's modified Eagle's medium with $10 \%$ fetal bovine serum for 10 days at $37^{\circ} \mathrm{C}$ in a $5 \% \mathrm{CO}_{2}$ incubator. The medium was changed every 3 days. For purification, the flasks were first shaken at $180 \mathrm{rpm}$ for $1 \mathrm{~h}$ to remove microglia and at $200 \mathrm{rpm}$ for $16 \mathrm{~h}$ with freshly-changed medium at $37^{\circ} \mathrm{C}$ to collect OPCs. The collected cells were allowed to adhere to uncoated plates for $0.5 \mathrm{~h}$ twice to remove contaminating cells. The purified OPCs were collected by gently shaking the plate and seeding them at 5,000 cells $/ \mathrm{cm}^{2}-50,000$ cells/ $\mathrm{cm}^{2}$ on coverslips that had been coated with poly- $D$-lysine the previous day. Finally, OPCs were cultured in Neurobasal medium supplemented with $2 \% \quad$ B27 for differentiation.

\section{Immunocytofluorescence Staining}

Cells on coverslips were fixed in $4 \%$ paraformaldehyde $(\mathrm{PFA})$ in $1 \times$ PBS at room temperature for $15 \mathrm{~min}$ before 
A<smiles>O=C(O)C1=CC(O)C(O)C(O)C1</smiles>

C

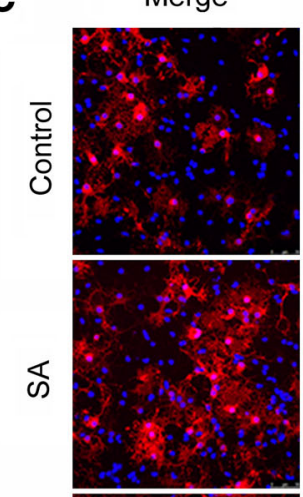

B

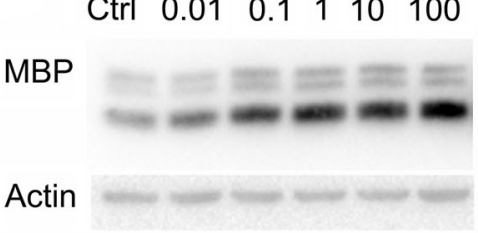

MBP

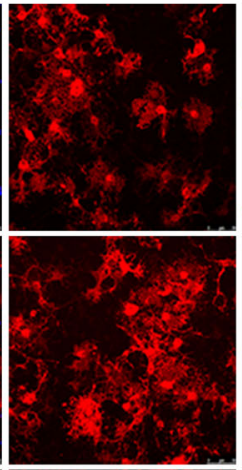

Hoechst
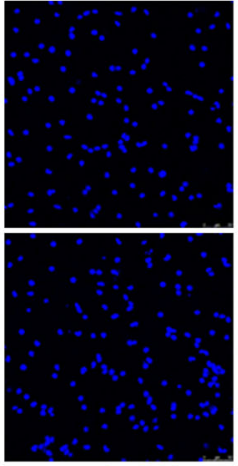

$\stackrel{m}{\bullet}$
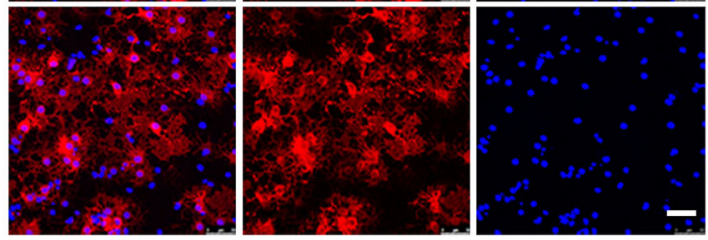

D

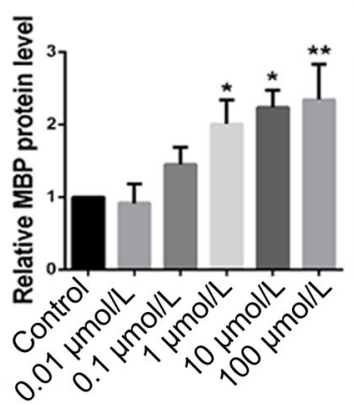

E

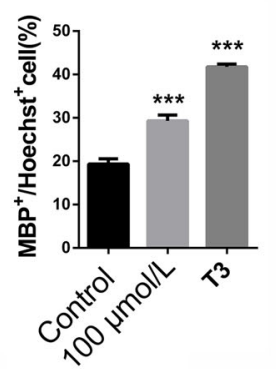

Fig. 1 SA increased myelin basic protein (MBP) expression in OPCs in vitro. A Structural formula of SA. B Western blots of MBP expression after $0.01 \mu \mathrm{g} / \mathrm{mL}, 0.1 \mu \mathrm{g} / \mathrm{mL}, 1 \mu \mathrm{g} / \mathrm{mL}, 10 \mu \mathrm{g} / \mathrm{mL}$, and $100 \mu \mathrm{g} / \mathrm{mL}$ SA treatment in cultured primary OPCs. C Representative images of immunofluorescence staining for MBP (red) in vehicle, SA $(100 \mu \mathrm{g} / \mathrm{mL})$, and T3 groups. D Quantification of the relative expression levels of MBP protein as in B. E Numbers of MBPpositive cells as in $\mathbf{C}$. Data are shown as mean \pm SEM. $* P<0.05$, ${ }^{* *} P<0.01,{ }^{* * *} P<0.001$, one-way ANOVA with Tukey's post hoc test. Scale bar, $50 \mu \mathrm{m}$.

washing 3 times with $1 \times$ PBS, followed by permeabilization with $0.1 \%$ Triton $\mathrm{X}-100$ for $15 \mathrm{~min}$. Then the cells were incubated overnight at $4{ }^{\circ} \mathrm{C}$ with primary antibody (myelin basic protein [MBP], 1:50, Chemicon, Temecula, CA; NG2, 1:200, Millipore, Etobicoke, Ontario, Canada). Then the cells were incubated with the corresponding fluorescein isothiocyanate- or tetramethylrhodamine- conjugated secondary antibody (1:100, Jackson ImmunoResearch, West Grove, PA) and Hoechst 33342 (1:1000) for $1 \mathrm{~h}$ at room temperature. Images were captured with a fluorescence microscope (DXM1200; Nikon, Tokyo, Japan).

\section{Immunohistofluorescence Staining}

Animals were anesthetized and perfused with 4\% PFA. Spinal cord tissue was embedded and sectioned, and postfixed in PFA overnight at $4^{\circ} \mathrm{C}$. Tissue sections were first boiled in $10 \mathrm{mmol} / \mathrm{L}$ citrate buffer $(\mathrm{pH} 6.0)$ for $20 \mathrm{~min}$ at $96^{\circ} \mathrm{C}$, then permeabilized with $0.3 \%$ Triton $\mathrm{X}-100$ for $30 \mathrm{~min}$ and blocked by $5 \%$ donkey serum for $1 \mathrm{~h}$. The sections were incubated overnight at $4^{\circ} \mathrm{C}$ with primary antibody (CC1, 1:100, Millipore; GFAP, 1:200, Sigma; IBA1, 1:200, Abcam, Cambridge, UK), and then with the corresponding secondary antibody for $1 \mathrm{~h}$ at room temperature. Last, the samples were examined under a confocal microscope (Leica, Buffalo Grove, IL).

\section{Western Blot Analysis}

After treatment with SA or vehicle for $72 \mathrm{~h}$, cells were homogenized in RIPA buffer (Beyotime, Shanghai, China) supplemented with the protease inhibitor
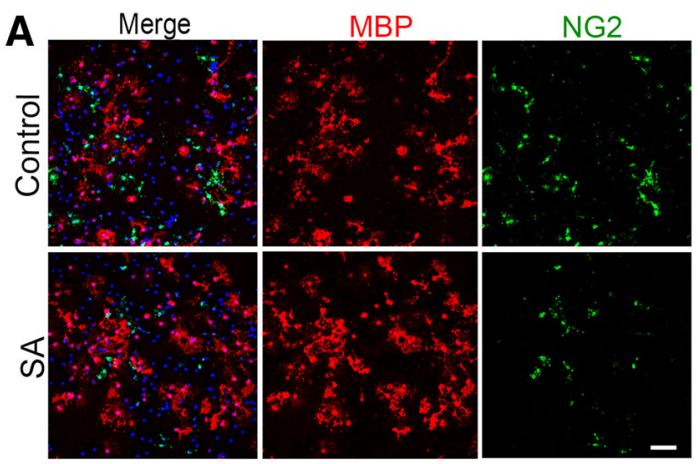

B

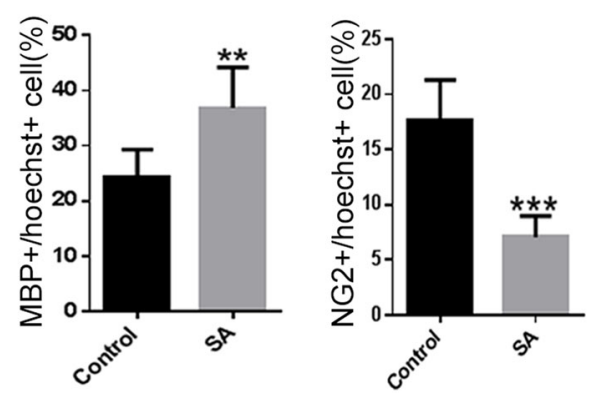

Fig. 2 SA decreases the number of NG2-positive cells in OPCs in vitro. A Representative images of immunofluorescence staining for MBP (red) and NG2 (green) in vehicle and SA $(100 \mu \mathrm{g} / \mathrm{mL})$ groups. B Numbers of MBP- and NG2-positive cells as in A. Data are shown as mean $\pm \mathrm{SD}$. $* * P<0.01, * * * P<0.001$, Student's $t$-test. Scale bar, $50 \mu \mathrm{m}$. 


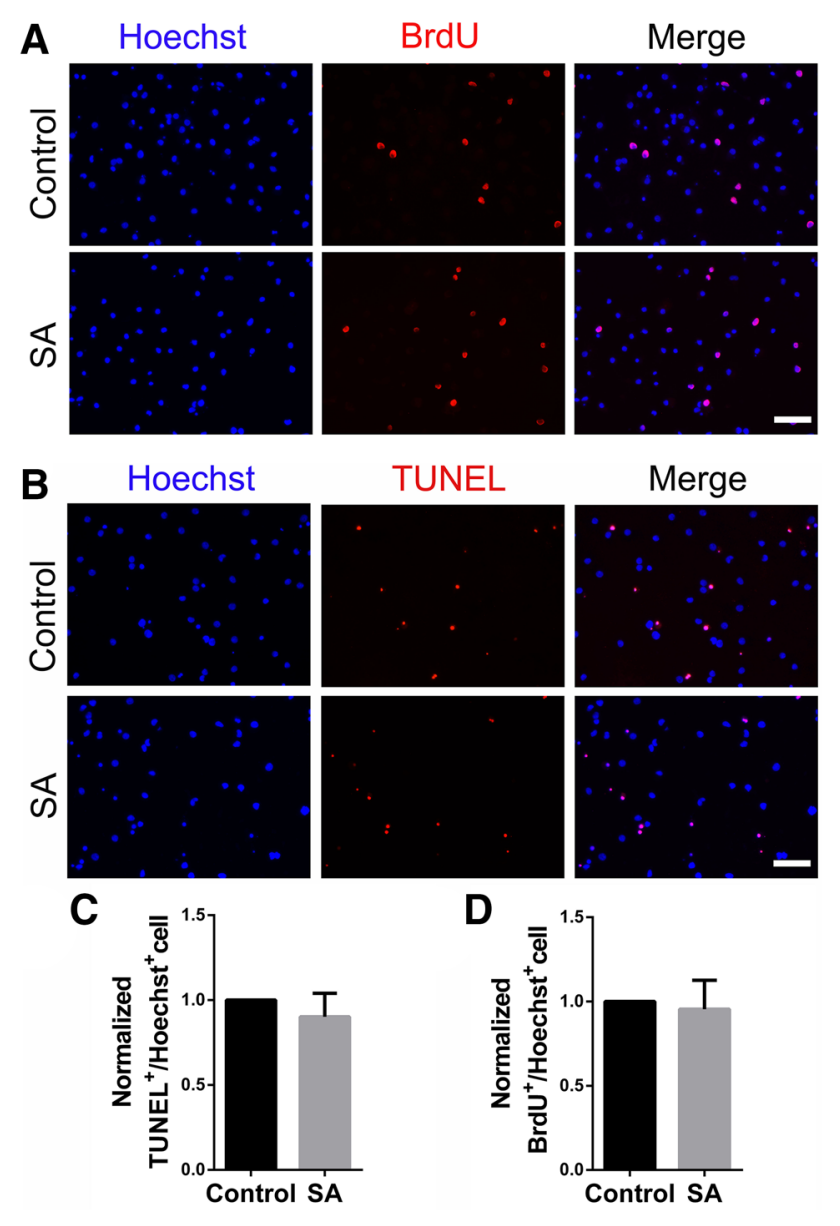

Fig. 3 SA does not affect proliferation and apoptosis of OPCs. A, B Representative images of BrdU-positive proliferating cells (red) (A) and TUNEL-positive apoptotic cells (red) (B) in SA (100 $\mu \mathrm{g} /$ $\mathrm{mL}$ )- and vehicle-treated OPCs. C, D Ratios of $\mathrm{TUNEL}^{+} / \mathrm{Hoechst}^{+}$ and $\mathrm{BrdU}^{+} / \mathrm{Hoechst}^{+}$cells in SA $(100 \mu \mathrm{g} / \mathrm{mL})$ - and vehicle-treated groups. Data are shown as mean $\pm \mathrm{SD}$. Student's $t$-test. Scale bars, $50 \mu \mathrm{m}$

phenylmethylsulfonyl fluoride (Beyotime). Then, cell lysates were subjected to Western blotting with a standard protocol as previously described [18, 19]. The primary antibodies used were anti-MBP (1:500), mTOR (1:3000, CST, Danvers, MA), p-mTOR (1:3000, CST) and the secondary antibodies were horseradish peroxidase conjugated anti-actin (1:50000; Kangchen Biotechnology, Shanghai, China). The primary antibodies were diluted in $1 \times$ TBST and samples were incubated overnight at $4^{\circ} \mathrm{C}$. After washing with $1 \times$ TBST, samples were incubated with secondary antibodies for $1 \mathrm{~h}$. The protein bands were analyzed and quantified using Image Lab (Bio-Rad, Hercules, CA).

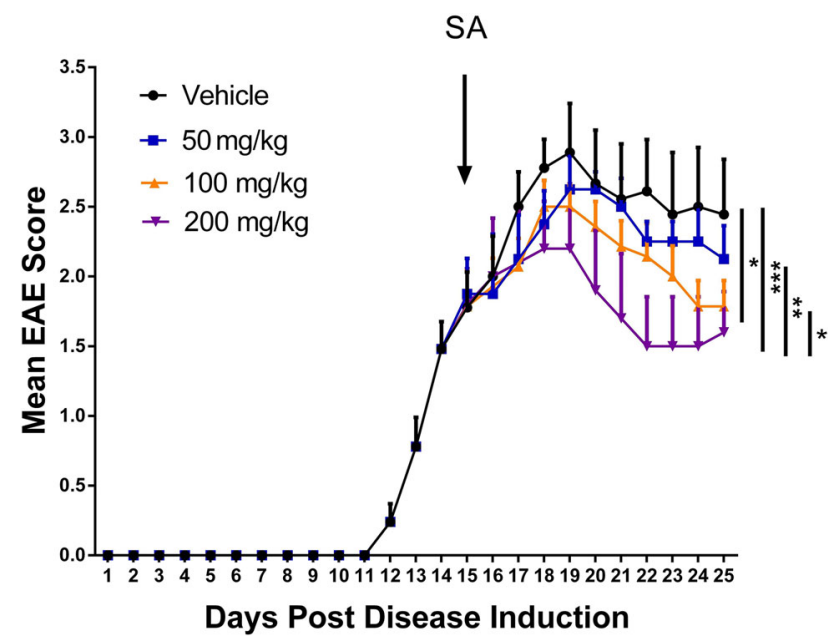

Fig. 4 SA ameliorates progression of EAE. The graph shows the daily clinical EAE score in the SA $(50 \mathrm{mg} / \mathrm{kg}, 100 \mathrm{mg} / \mathrm{kg}$, and $200 \mathrm{mg} / \mathrm{kg}$ ) and vehicle groups (once a day from $15 \mathrm{dpi}$ ). Analysis showed significant differences among the groups. Data are shown as mean $\pm \mathrm{SEM}, \quad n=5 /$ group in each experiment; $* P<0.05$, $* * P<0.01, * * * P<0.001$, the nonparametric Mann-Whitney U test was used to compare two groups and the Kruskal-Wallis test with Dunn's post hoc test to compare four groups.

\section{BrdU Incorporation and TUNEL Assays}

BrdU (5-bromo-2-deoxyuridine, $10 \mu \mathrm{mol} / \mathrm{L}$; Sigma) was added to the medium and incubated for $6 \mathrm{~h}$ to label proliferating cells. After fixation in 4\% PFA, cells were rinsed three times with $1 \times$ PBS for 5 min, permeabilized with $0.3 \%$ Triton $\mathrm{X}-100$ for $10 \mathrm{~min}$, then incubated in $2 \mathrm{~N}$ $\mathrm{HC} 1$ for $30 \mathrm{~min}$ and neutralized in $0.1 \mathrm{~mol} / \mathrm{L}$ sodium borate for $25 \mathrm{~min}$. Finally, the cells were incubated with primary anti-BrdU (1:100, Sigma) overnight at $4^{\circ} \mathrm{C}$ as described for Immunocytofluorescence Staining above.

TUNEL assays were carried out with the in situ cell death detection kit, TMR red (12156, Roche, Indianapolis, IN), according to the manufacturer's instructions. After fixation in $4 \%$ PFA, samples were incubated with the TUNEL reaction solution mixture for $1 \mathrm{~h}$ at $37^{\circ} \mathrm{C}$ and then stained with Hoechst 33342 for 5 min at room temperature.

\section{Histological Staining}

The spinal cords were isolated from LPC and EAE mice and cut into continuous paraffin sections $(4 \mu \mathrm{m})$. For Luxol fast blue (LFB) staining, sections were stained with LFB solution overnight in a humid incubator at $60^{\circ} \mathrm{C}$, then rinsed with $95 \%$ ethanol for $5 \mathrm{~min}, 0.05 \%$ lithium carbonate, and $70 \%$ ethanol for $20 \mathrm{~s}$, then washed with water.

For hematoxylin and eosin (H\&E) staining, sections were stained with hematoxylin for $3 \mathrm{~min}-5 \mathrm{~min}$, then rinsed in ethanol with $1 \% \mathrm{HCl}$ for $10 \mathrm{~s}$ and $1 \%$ ammonia water, then counterstained with eosin. After dehydration 
Fig. 5 SA inhibits inflammation and demyelination in the CNS of EAE mice. A, B Representative images of fluoromyelin (A) and Luxol fast blue staining $(\mathbf{B})$ of spinal cord sections in EAE mice in the SA and vehicle groups at $25 \mathrm{dpi}$. C Representative images of H\&E staining showing infiltrating cells in spinal cord sections from EAE mice in the SA and vehicle groups at $25 \mathrm{dpi}$. D, E Quantitative analysis of the demyelination area and number of infiltrating cells as in $\mathbf{B}$ and C. Data are shown as mean \pm SEM, $n=5 /$ group in each experiment, $* P<0.05$, $* * P<0.01, * * * P<0.001$, one-way ANOVA with Tukey's post hoc test. Scale bars, $100 \mu \mathrm{m}$.
A

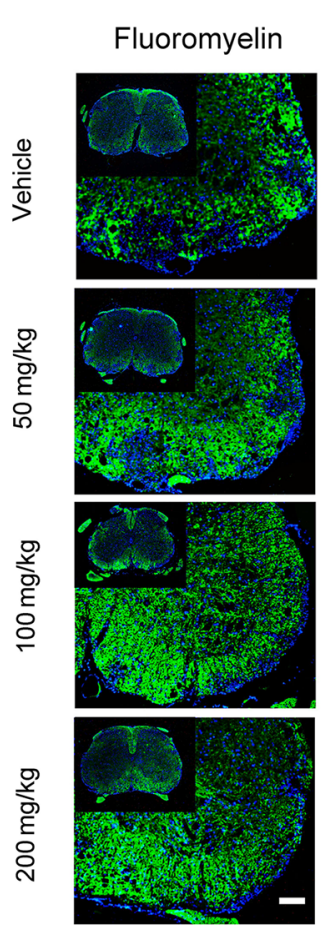

B LFB

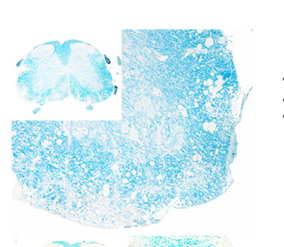

C
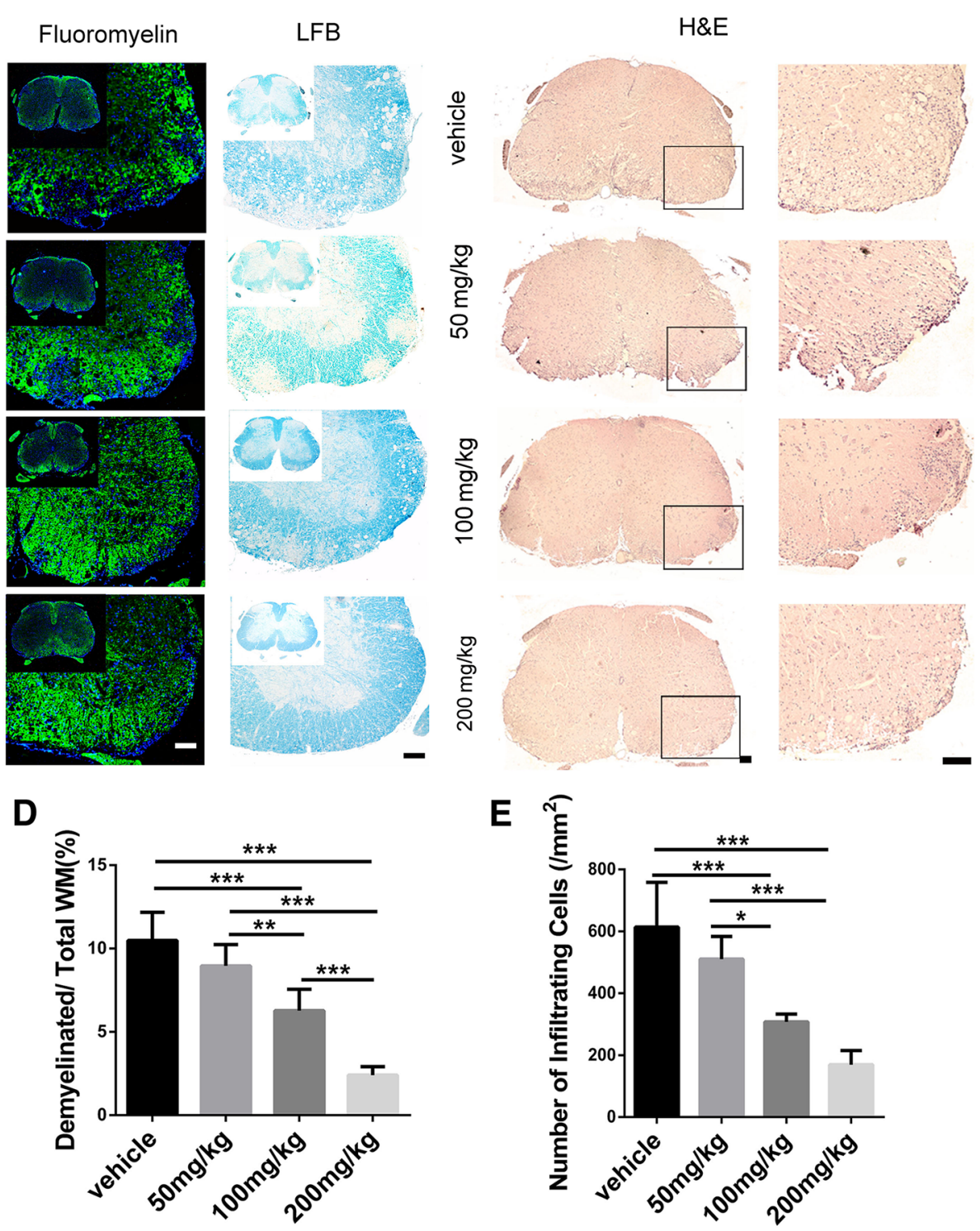

through a series of graded ethanols and cleared with xylene, the sections were mounted in Permount mounting medium (Fisher Scientific, Pittsburgh, PA).

\section{Statistical Analyses}

Data are presented as mean $\pm \mathrm{SD}$ or mean $\pm \mathrm{SEM}$ from at least three independent experiments unless otherwise indicated. One-way ANOVA with Tukey's post hoc test was used for multiple groups and Student's $t$ test for two groups. The EAE model was analyzed using the nonparametric Mann-Whitney $U$ test to compare two groups or the Kruskal-Wallis test with Dunn's post hoc test to compare four groups. $P<0.05$ was considered statistically significant.

\section{Results}

\section{SA Promotes the Expression of Myelin Basic Protein (MBP) in OPCs In Vitro}

To unravel the effect of SA on the differentiation of OPCs, we assessed the expression of MBP in cultured OPCs treated with SA $(0.01 \mu \mathrm{g} / \mathrm{mL}, 0.1 \mu \mathrm{g} / \mathrm{mL}, 1 \mu \mathrm{g} / \mathrm{mL}, 10 \mu \mathrm{g} /$ $\mathrm{mL}$, and $100 \mu \mathrm{g} / \mathrm{mL}$ ) and vehicle for $72 \mathrm{~h}$. We found that MBP was up-regulated after SA administration $(1 \mu \mathrm{g} / \mathrm{mL}$, $10 \mu \mathrm{g} / \mathrm{mL}$, and $100 \mu \mathrm{g} / \mathrm{mL})$, in a dose-dependent manner. The highest level of MBP expression was found in the $100 \mu \mathrm{g} / \mathrm{mL}$ SA treatment group (Fig. 1B, D), showing a 2-fold increase over vehicle-treated cells. Hence, we used $100 \mu \mathrm{g} / \mathrm{mL}$ as the standard concentration for all in vitro 
experiments unless otherwise stated. These results were also confirmed by immunocytochemistry. Three days after SA treatment, the proportion of MBP-positive mature OLs was significantly higher than in the control group (Fig. 1C, $\mathrm{E}$ ), which was in line with the results obtained with $\mathrm{T} 3$ administration as a positive control. To further determine whether SA accelerates the differentiation process from OPCs to mature OLs, we co-stained for NG2 and MBP in SA- and vehicle-treated OPCs. We found that the number of NG2-positive cells was clearly down-regulated while that of MBP-positive cells was up-regulated (Fig. 2A, B). These results revealed that SA could promote the differentiation and maturation of OPCs in vitro.

\section{SA Does not Affect Proliferation and Apoptosis of OPCs}

To investigate whether SA regulates the proliferation and apoptosis of OPCs, BrdU incorporation and TUNEL assays were carried out. The results showed no difference in the ratio of $\mathrm{BrdU}^{+}$cells between the SA-treated and control groups (Fig. 3A, D), indicating that SA had no effect on OPC proliferation. In addition, there was no significant difference in TUNEL-positive cells between the SA-treated and control groups (Fig. 3B, C). Taken together, these results suggested that $\mathrm{SA}$ specifically promotes the maturation of OPCs without affecting their proliferation and apoptosis.

\section{SA Alleviates EAE Progression}

EAE is the most common animal model for demyelinating diseases. Based on the previous finding that SA could promote OPC differentiation in vitro, we administered SA to EAE mice to investigate its therapeutic effect. The experimental results showed no significant difference in behavioral score between the low-dose $(50 \mathrm{mg} / \mathrm{kg} \mathrm{SA})$ and control groups. However, the EAE scores were significantly lower in the 100 and $200 \mathrm{mg} / \mathrm{kg}$ SA groups, and the effect of $200 \mathrm{mg} / \mathrm{kg}$ SA group was relatively stronger (Fig. 4).

\section{SA Inhibits CNS Inflammation and Demyelination}

Then we used Fluoromyelin, LFB, and H\&E staining to examine the spinal cord of EAE mice in the different groups. Fluoromyelin and LFB staining showed no significant difference in the demyelination area between the $50 \mathrm{mg} / \mathrm{kg} \mathrm{SA}$ and control groups, while that of the $100 \mathrm{mg} /$ $\mathrm{kg}$ and $200 \mathrm{mg} / \mathrm{kg} \mathrm{SA}$ groups was smaller than the control group, with $200 \mathrm{mg} / \mathrm{kg} \mathrm{SA}$ group displaying the smallest area of demyelination (Fig. 5A, B, D). H\&E staining showed no significant difference between the number of inflammatory cells in the $50 \mathrm{mg} / \mathrm{kg}$ SA group and that in the control group. The numbers of inflammatory infiltrating cells in the lesions of the $100 \mathrm{mg} / \mathrm{kg}$ and $200 \mathrm{mg} / \mathrm{kg} \mathrm{SA}$ groups were significantly reduced, and the $200 \mathrm{mg} / \mathrm{kg}$ group was lower (Fig. 5C, E). Immunofluorescence staining for GFAP and IBA1 (Fig. 6A, B) showed that the numbers of astrocytes and microglia were lower in all SA groups while the effects of $100 \mathrm{mg} / \mathrm{kg}$ and $200 \mathrm{mg} / \mathrm{kg} \mathrm{SA}$ were more apparent (Fig. 6C, D). These results

A

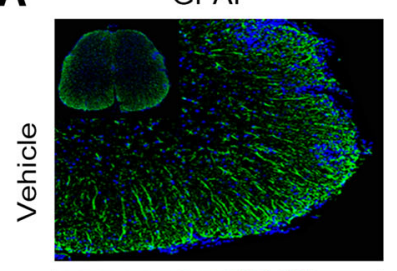

B
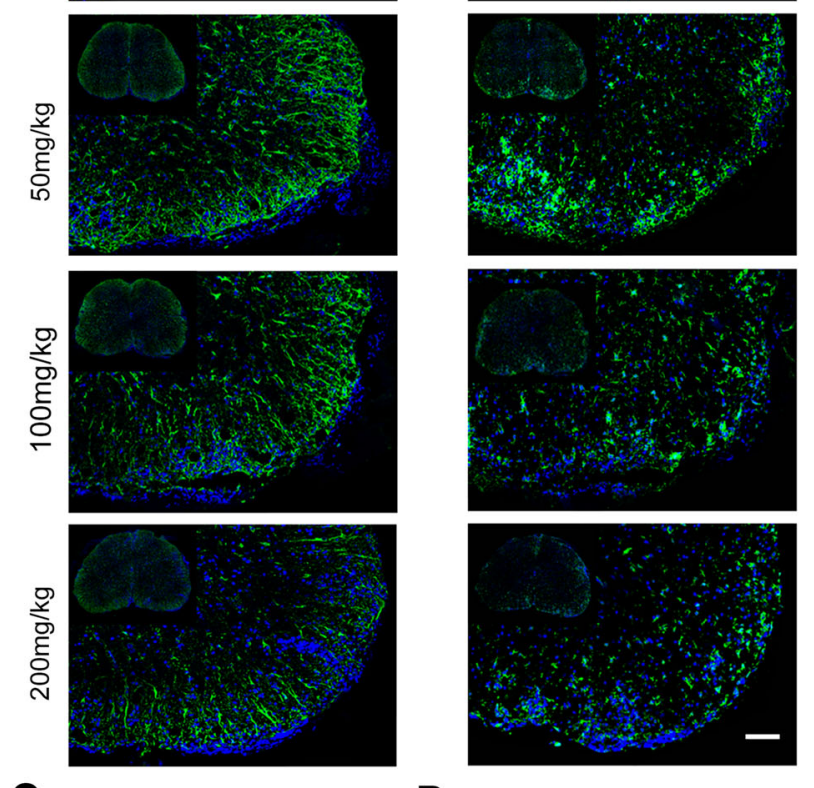

C
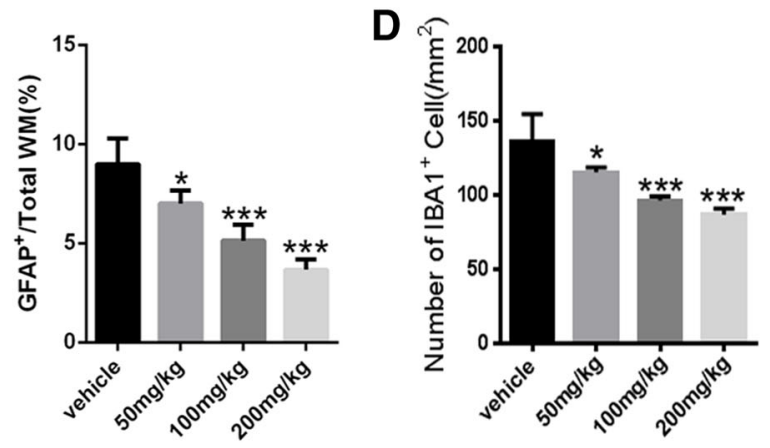

Fig. 6 SA downregulates $\mathrm{GFAP}^{+}$and $\mathrm{IBA}^{+}$cells in the $\mathrm{CNS}$ of EAE mice. A, B Representative immunofluorescence images showing GFAP (green) and IBA1 (green) positive cells in spinal cord sections from EAE mice in the SA and vehicle groups at $25 \mathrm{dpi}$. C, D Numbers of $\mathrm{GFAP}^{+}$and $\mathrm{IBA}^{+}$cells as in $\mathbf{A}$ and $\mathbf{B}$. Data are shown as mean $\pm \mathrm{SEM}, n=5$ /group in each experiment, $* P<0.05$, $* * * P<0.001$, one-way ANOVA with Tukey's post hoc test. Scale bar, $100 \mu \mathrm{m}$. 
Fig. 7 SA enhances remyelination in LPC-induced focal demyelination lesions.

A Schematic illustrating the injection site and the timing of the LPC model as well as the time SA was administered. B, C Representative images of Fluoromyelin (B) and LFB staining (C) showing the demyelinated region in the dorsal column of the spinal cord. D Quantification of the volume of demyelination as in $\mathbf{B}$ and $\mathbf{C}$. Data are shown as the mean \pm SEM,

$n=5 /$ group in each experiment. $* P<0.05$, ** $P<0.01$, $* * * P<0.001$, one-way ANOVA with Tukey's post hoc test. Scale bars, $100 \mu \mathrm{m}$.
A

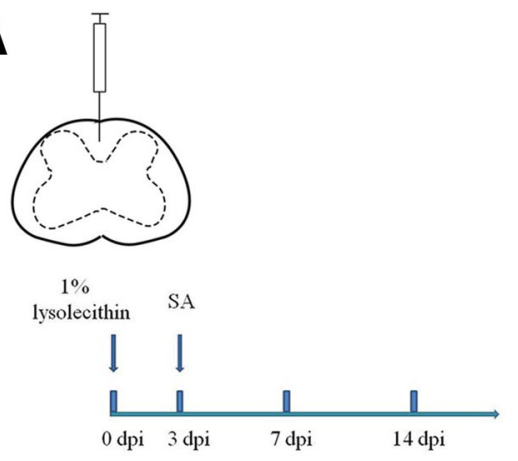

D

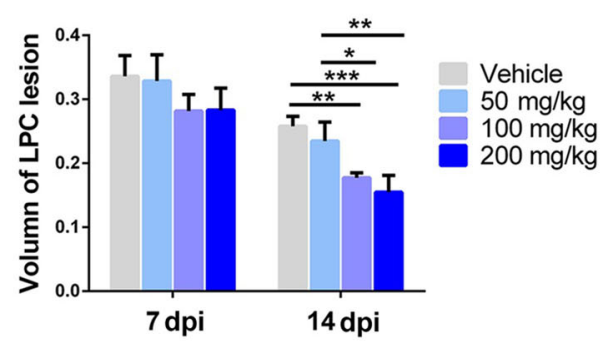

B

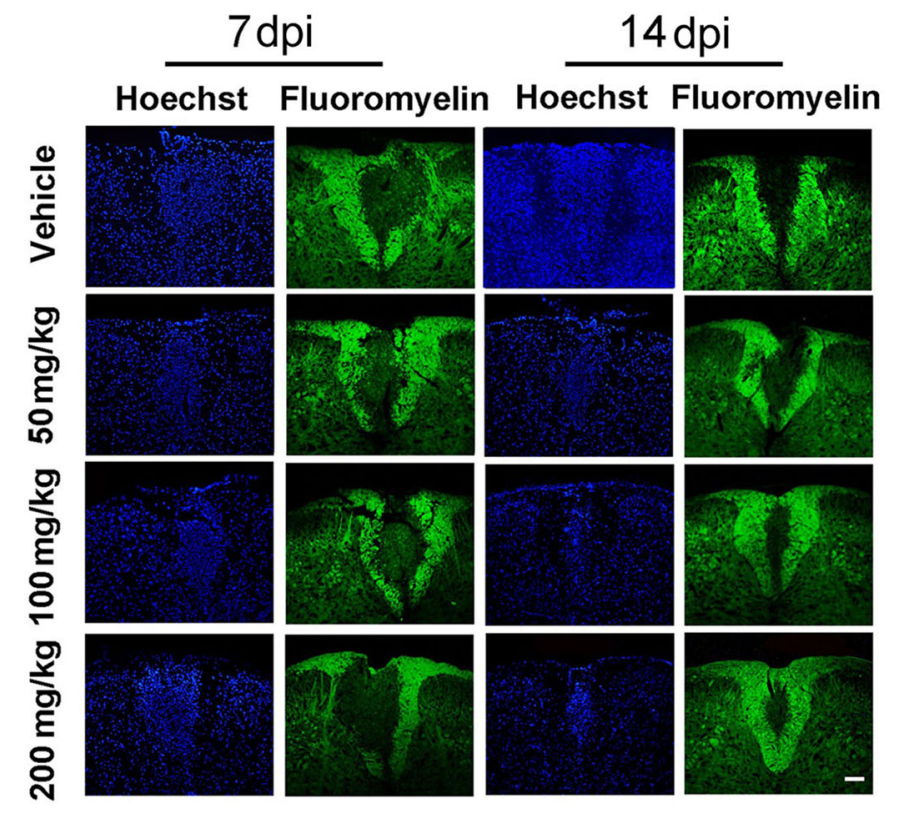

C
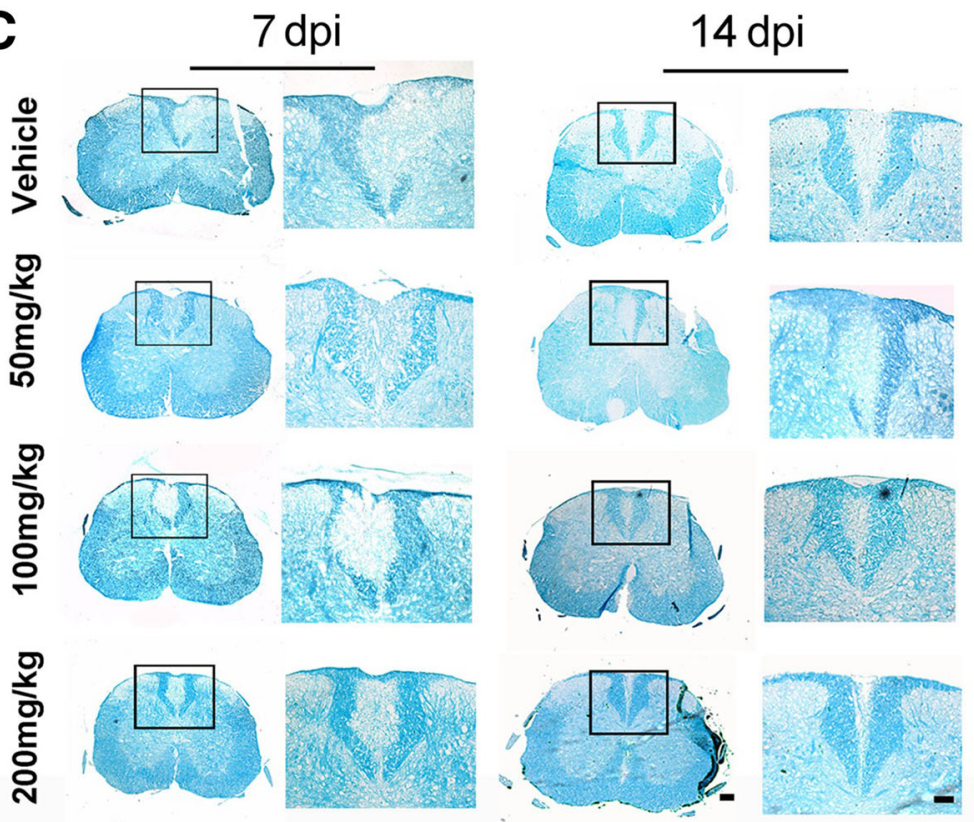
demonstrated that SA could reduce the demyelination and inhibit the infiltration of inflammatory cells in the CNS of EAE mice.

\section{SA Promotes Remyelination in LPC-Induced Focal Demyelination Model}

EAE is a chronic demyelinating model induced by inflammation [21]. To clarify the specific impact of SA in promoting OPC differentiation and maturation in vivo, we further explored the effect of SA on the LPC-induced focal demyelination model (Fig. 7A), a non-T cell-dependent model [22]. The LPC model shows demyelination at 3 dpi, displays the maximum area of demyelination at $7 \mathrm{dpi}$, and exhibits clear remyelination at 14 dpi $[45,46]$. From $3 \mathrm{dpi}$, SA or vehicle was administered daily. The results of Fluoromyelin and LFB staining showed no significant difference in the demyelination volume at $7 \mathrm{dpi}$ among the different groups (Fig. 7B, D). However, at $14 \mathrm{dpi}$, the demyelination volume was significantly decreased in the SA-treated groups $(100 \mathrm{mg} / \mathrm{kg}$ and $200 \mathrm{mg} / \mathrm{kg})$, suggesting that SA promotes remyelination in the LPC model (Fig. 7C, D). To further verify that the remyelinationpromoting effect of SA is due to an increase in newlygenerated OLs from OPCs rather than pre-existing OLs, we assessed the numbers of mature OLs by immunofluorescence with $\mathrm{CC} 1$ antibody in the different groups. The number of $\mathrm{CC}^{+}$cells in the center of lesions was significantly higher in the SA groups $(100 \mathrm{mg} / \mathrm{kg}$ and $200 \mathrm{mg} / \mathrm{kg}$ ) than in the control group at $14 \mathrm{dpi}$ (Fig. 8A, B). This result was consistent with our previous in vitro experiments and suggested that SA does promote the differentiation of OPCs in the LPC-induced focal demyelination lesions. We also found that different doses of SA decreased the numbers of $\mathrm{GFAP}^{+}$astrocytes and $\mathrm{IBA}^{+}$ microglia (Fig. 9).

\section{SA Promotes the Differentiation of OPCs by Acti- vating the mTOR Signaling Pathway}

Previous studies have demonstrated that both the Ras/Raf/ Mek/Erk and the PI3 K/Akt/mTOR pathways play important roles during OL lineage progression [23-26]. To reveal the pathway targeted by SA, we assessed the MBP expression in OPCs treated with different inhibitors plus SA. Adding rapamycin or U0126 alone to the OPC medium significantly reduced the expression of MBP (Fig. 10A, B), consistent with a previous report [26]. However, rapamycin, an mTOR inhibitor, dramatically blocked the increase of MBP expression in the $100 \mu \mathrm{g} / \mathrm{mL}$ SA group, but the MEK inhibitor U0126 did not (Fig. 10A, B). Meanwhile, the increased MBP-positive cells with SA treatment were diminished after rapamycin was added to the culture
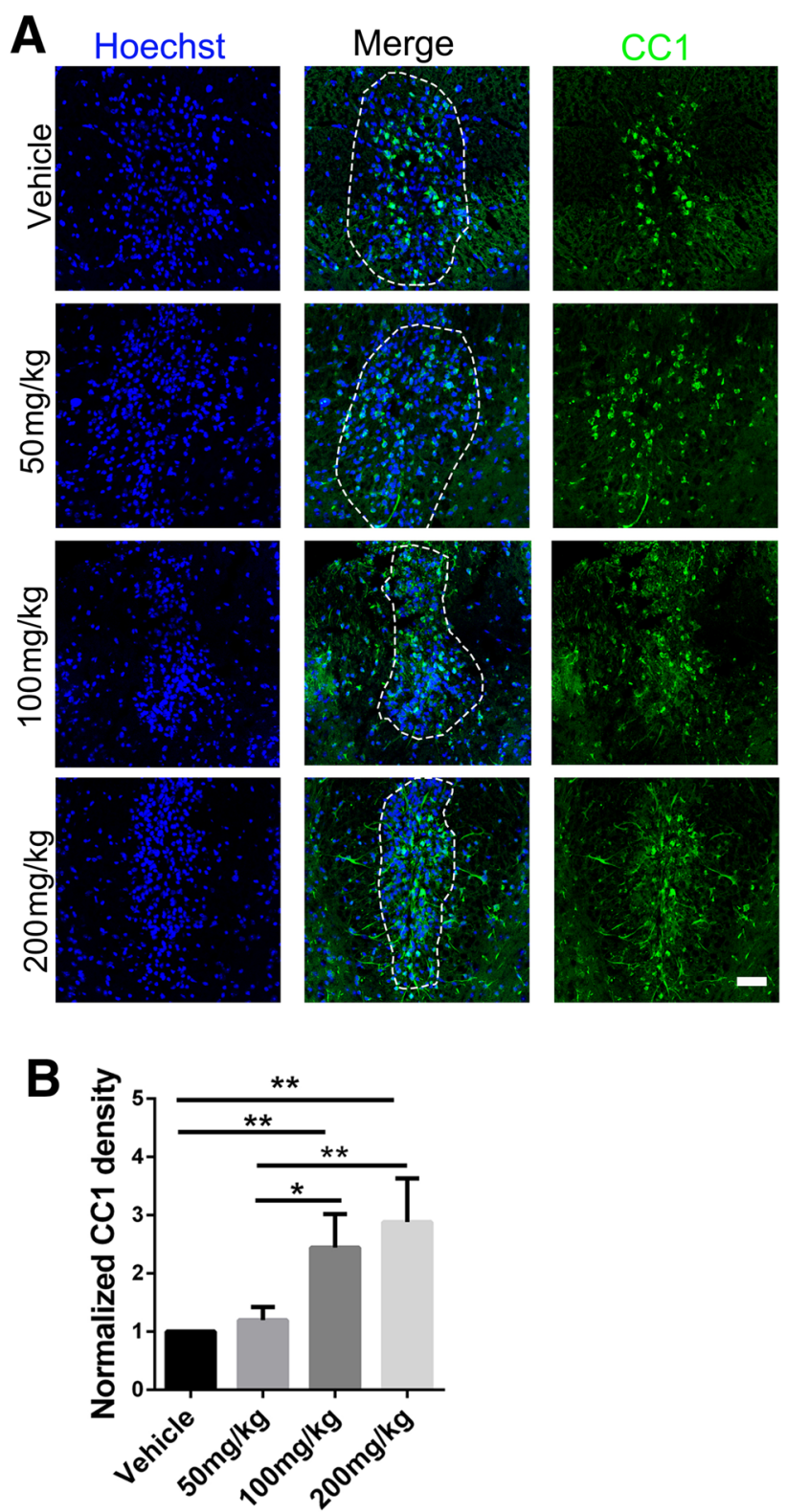

Fig. 8 SA increases the number of mature OLs during remyelination in LPC lesions. A Representative immunofluorescence images showing CC1 (green) positive cells within the lesion (approximated by dotted line) at $14 \mathrm{dpi}$ in SA $(50 \mathrm{mg} / \mathrm{kg}, 100 \mathrm{mg} / \mathrm{kg}$, and $200 \mathrm{mg} /$ $\mathrm{kg}$ ) and vehicle-treated mice. B Ratios of CC1-positive cells per lesion area as in A. Data are shown as mean \pm SEM, $n=5$ /group in each experiment, $* P<0.05, * * P<0.01$, one-way ANOVA with Tukey's post hoc test. Scale bar, $100 \mu \mathrm{m}$.

(Fig. 10C, D). Moreover, the level of phosphorylated mTOR was significantly elevated after SA treatment compared with the control group (Fig. 10E, F). To verify that the differentiation-promoting effect of SA is mediated by the PI3 K/Akt/mTOR pathway, we incubated OPCs with SA plus Wortmannin and LY294002 which are inhibitors of PI3 K, an up-stream molecule in the Akt/ mTOR pathway (Fig. 10G, H). Western blot indicated that 
Fig. 9 SA reduces the ratio of $\mathrm{GFAP}^{+}$and $\mathrm{IBA}^{+}{ }^{+}$cells during remyelination in LPC lesions.

A, B Representative

immunofluorescence images showing GFAP (A) and IBA1

(B) positive cells within the lesions at $14 \mathrm{dpi}$ in the SA $(50 \mathrm{mg} / \mathrm{kg}, 100 \mathrm{mg} / \mathrm{kg}$, and $200 \mathrm{mg} / \mathrm{kg}$ ) and vehicle groups. C, D Ratios of GFAP (C) and IBA1 (D) positive cells per lesion area as in $\mathbf{A}$ and $\mathbf{B}$. Data are shown as mean \pm SEM, $n=5$ /group in each experiment, $* P<0.05, * * P<0.01$, $* * * P<0.001$, one-way ANOVA with Tukey's post hoc test. Scale bar, $100 \mu \mathrm{m}$.
A
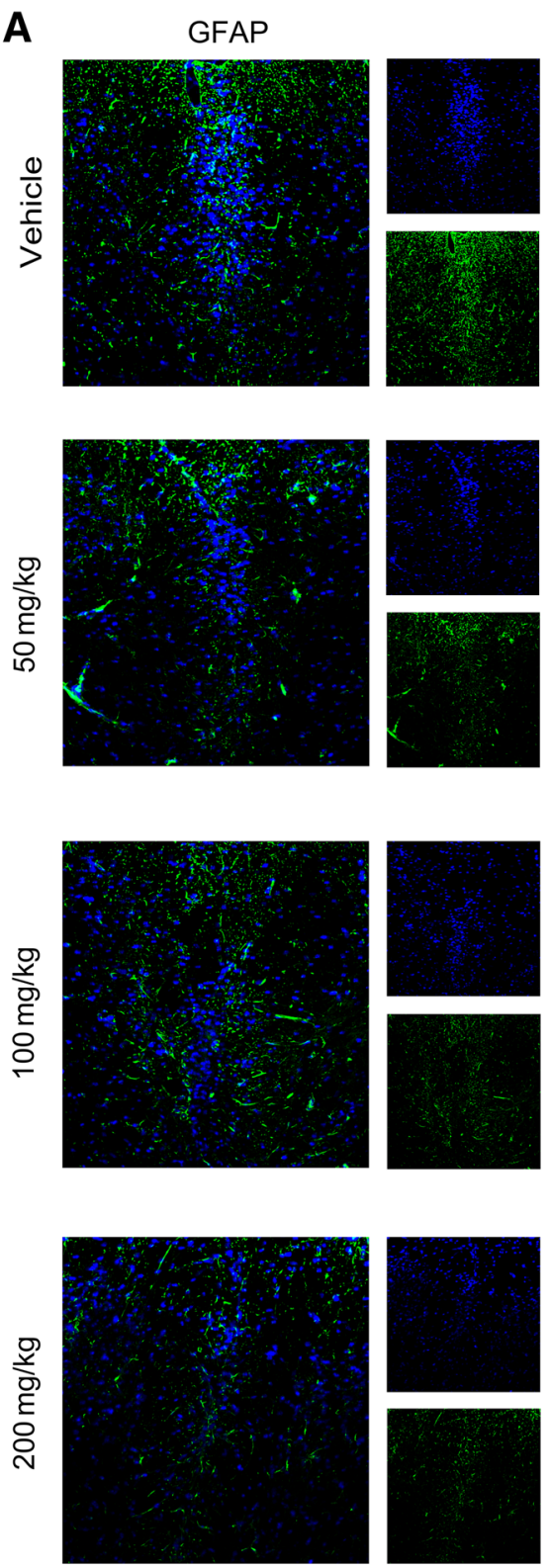

C

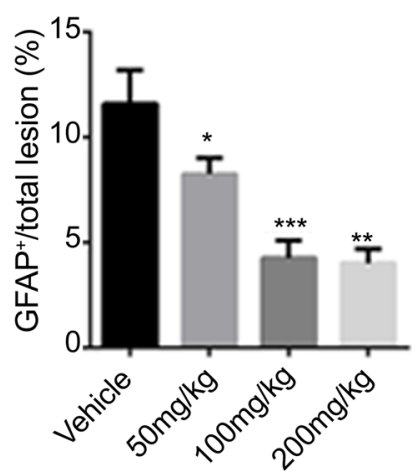

B
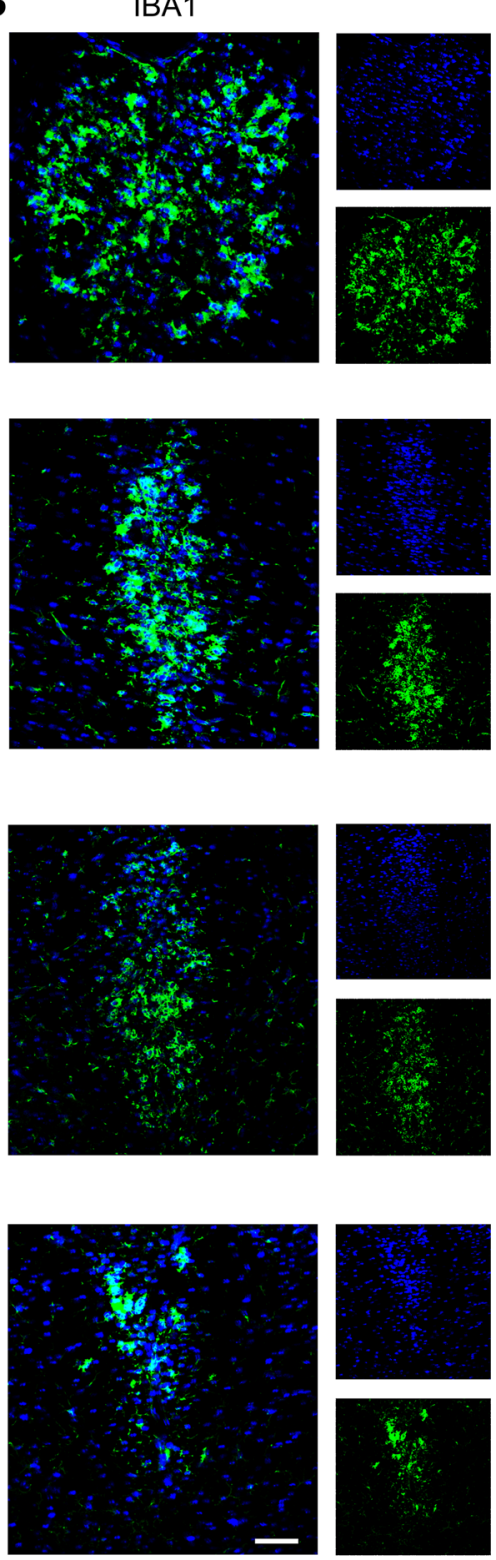

D

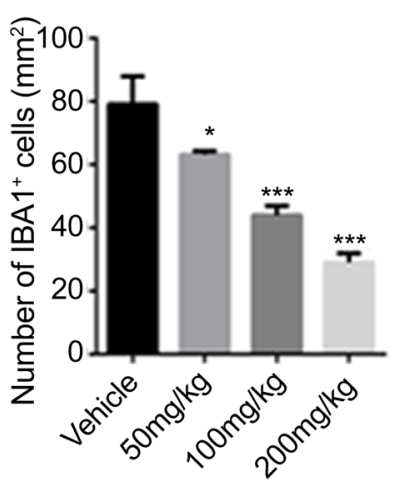


A

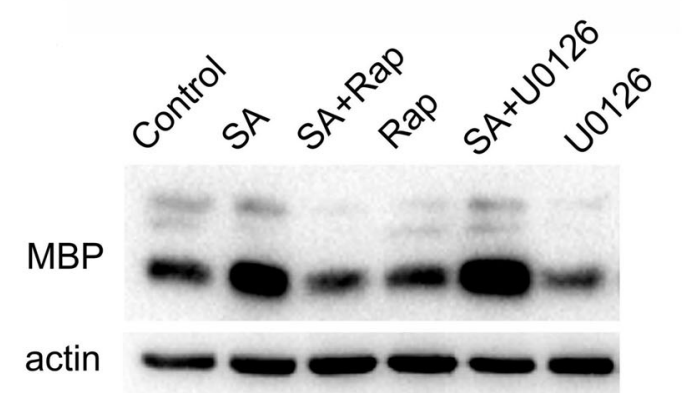

C

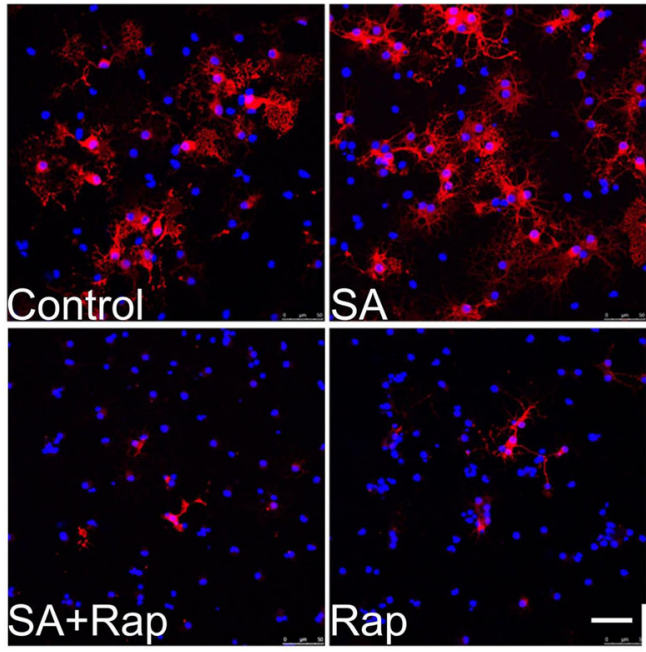

E

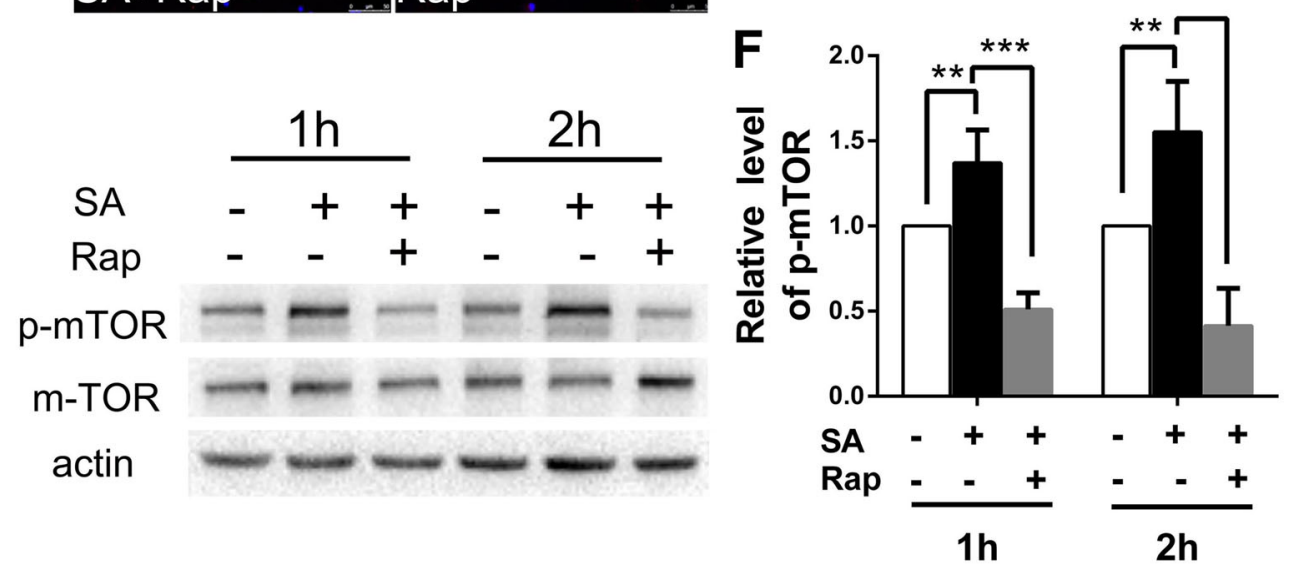

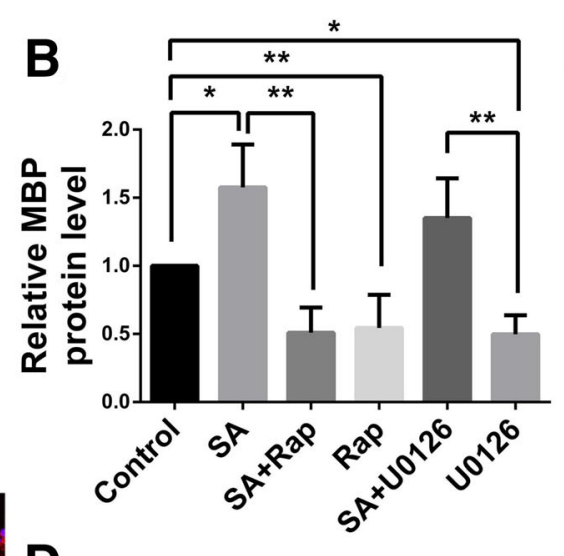

D

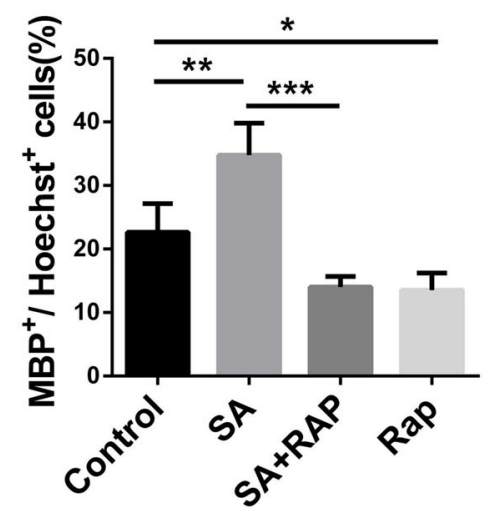

H

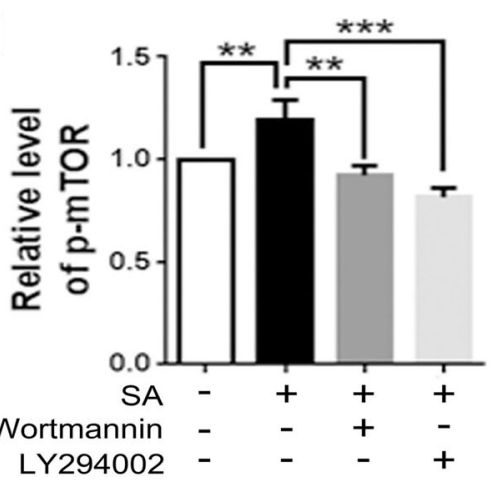


4Fig. 10 SA promotes OPC differentiation through activating the mTOR pathway. A Western blots showing the MBP expression in OPCs induced by SA plus the mTOR inhibitor rapamycin (Rap) $(10 \mathrm{nmol} / \mathrm{L})$ or the Erk1/2 inhibitor U0126 $(2 \mathrm{nmol} / \mathrm{L})$ and their control groups. B Relative expression levels of MBP protein as in A. C Representative immunofluorescence images showing MBPpositive cells (red) in the SA plus Rap group versus its controls. D Numbers of MBP-positive cells as in C. E Western blots showing the p-mTOR levels in the SA plus Rap group versus its controls. F Relative p-mTOR levels as in E. G Western blots showing the p-mTOR expression levels in SA plus wortmanin or LY294002 group versus its controls. H Relative p-mTOR levels as in G. Data are shown as mean $\pm \mathrm{SD} . * P<0.05, * * P<0.01$, $* * * P<0.001$, Student's $t$-test. Scale bar, $50 \mu \mathrm{m}$.

both inhibitors of PI3 K reduced the phosphorylation level of mTOR to the level of the vehicle control. Taken together, our results indicated that SA could promote the differentiation of OPCs via the PI3 K/Akt/mTOR signaling pathway.

\section{Discussion}

Generally, remyelination proceeds spontaneously in response to CNS demyelination, and this pathophysiological process depends on the differentiation and maturation of OPCs [27]. After demyelination, OPCs rapidly switch from the resting to the activated state, followed by recruitment, proliferation, and differentiation into mature OLs. Then, mature OLs form new myelin sheaths to protect axons and restore signal transmission [4, 28, 29]. Although they remain competent to restore myelin sheaths throughout adulthood, OPCs fail to remyelinate in some demyelinating diseases, such as MS, of which the main pathological features are inflammation-mediated demyelination and multifocal lesions with axonal degeneration [30]. At present, the therapeutic strategy for MS mainly depends on immunosuppression and immunomodulation to reduce the recurrence rate of relapsing-remitting MS, while there is no effective remedy for progressive MS [31, 32]. Previous studies have shown that the failure of remyelination in MS is mainly attributed to the inability of differentiation and maturation of OPCs [6, 33]. Therefore, it is of great importance to seek potential treatments to promote the differentiation and maturation of OPCs.

SA has been shown to protect the neuronal cell line SHSY5Y against oxidative stimulation which usually occurs under neurodegenerative conditions [9]. In addition, its derivative, 3,4-oxo-isopropylidene-shikimic acid, has been reported to have a similar protective effect for astrocytes and neurons in a rat model of cerebral ischemic injury [34]. However, whether SA has a beneficial impact on OPCs is unknown. In the present study, based on the vital function of myelination along with its specificity as a marker of mature OLs, MBP was selected as a target to test the effects of SA on OPC differentiation. SA showed a significant dose-dependent up-regulation of MBP expression. Consistently, the number of MBP-positive mature OLs marked by immunostaining increased remarkably after SA treatment. Meanwhile, SA reduced the number of NG2-positive OPCs. As SA did not affect the proliferation and apoptosis of OPCs, our results suggested that SA specifically promotes the differentiation and maturation of OPCs.

To directly assess the possible application of SA to demyelinating diseases, we assessed the effects of SA on EAE, the most commonly-used animal model for studying MS. We found that SA significantly inhibited the inflammation and demyelination and reduced the number of astrocytes and microglia in the spinal cord, and the overall neurological functional recovery in EAE mice was improved as well. It has been reported that SA inhibits lipopolysaccharide-induced cellular pro-inflammatory cytokines as well as attenuating mechanical hyperalgesia in mice [8] through inhibiting ERK 1/2 and p38 phosphorylation. We presume that the underlying mechanism of SA in EAE is similar, but this needs further investigation.

Since the pathogenesis of EAE is complex and involves a variety of interactions between the immune and nervous systems [35] and the demyelination and remyelination occur concurrently, it is difficult to distinguish between the reduction of demyelination and the promotion of remyelination [17]. In order to further assess the specific effects of SA on remyelination, we introduced a chemical injury model, that is, LPC-induced focal demyelination. In this model, demyelination and remyelination are generated along a reproducible timeline [36]. Most importantly, the interference of inflammatory factors in EAE can be avoided in the LPC model, which thus can simply and directly reflect the effect of a drug on remyelination [35]. Our data demonstrated that SA did not affect the demyelinating process in the LPC model at $7 \mathrm{dpi}$, while it did promote the maturation of OPCs together with remyelination at $14 \mathrm{dpi}$. We also found that the numbers of astrocytes and microglia were decreased after SA treatment in the LPC model; however, since these two types of cells play dual roles in the process of remyelination [37], it is still not clear whether they are supportive or destructive.

Both the Ras/Raf/Mek/Erk and the PI3 K/Akt/mTOR pathways play important roles in OL lineage progression [23-25]. Previous studies have shown that SA can suppress pain and pro-inflammatory factors by inhibiting the phosphorylation of Erk1/2 and p38 [12]. Besides, the Erk1/2 pathway is associated with the survival, proliferation, migration, and differentiation of OPCs and myelination $[26,38]$. However, in our study, an inhibitor of MEK, an 
upstream kinase of Erk, did not block the SA-induced differentiation-promoting effects on OPCs, suggesting that these effects are not associated with the Erk1/2 pathway. Several studies have shown that mTOR, a downstream effector of AKT signaling, is crucial for OPC differentiation and myelination $[23,39,40]$. Rapamycin, an mTOR inhibitor, can repress the differentiation of OPCs as well as the expression of most myelin proteins [26]. Consistently, our experimental results suggested that SA increased the level of phosphorylated mTOR, which could be blocked by rapamycin. And the $\mathrm{MBP}^{+} \mathrm{OL}$ up-regulation by SA was shown to be antagonized by rapamycin. We also verified that a PI3 K inhibitor lowered the level of phosphorylated mTOR to the blank control level. Interestingly, in our experiments either U0126 or rapamycin alone repressed the maturation of OPCs, but SA plus U0126 did not significantly inhibit the maturation process. A possible explanation for this is that both the Akt/mTOR and Mek/mTOR pathways activate mTORC1 by interacting with the TSC1/ TSC2 protein complex [41-43], so SA may activate mTOR and induce OPC differentiation via Akt when MEK is blocked by its inhibitor U0126. In the present study, we also found that SA promoted mTOR phosphorylation through the PI3 $\mathrm{K}$ pathway, which is in accord with previous research showing that SA activates the PI3 K/Akt pathway in hepatocytes [44]. Thus, the induction of OPC differentiation by SA may mainly be mediated by the $\mathrm{PI} 3 \mathrm{~K} / \mathrm{Akt} / \mathrm{mTOR}$ pathway.

In summary, we found for the first time that SA specifically promoted the differentiation and maturation of OPCs via the PI3 K/Akt/mTOR signaling pathway, alleviated the severity of EAE, and accelerated remyelination in the LPC model, suggesting the therapeutic potential of SA for demyelinating diseases.

Acknowledgements This work was supported by the National Natural Science Foundation of China (31571066 and 31771129) and the National Basic Research Development Program of China (2016YFA0100802).

Conflict of interest The authors declare that they have no conflict of interest.

Open Access This article is distributed under the terms of the Creative Commons Attribution 4.0 International License (http:// creativecommons.org/licenses/by/4.0/), which permits unrestricted use, distribution, and reproduction in any medium, provided you give appropriate credit to the original author(s) and the source, provide a link to the Creative Commons license, and indicate if changes were made.

\section{References}

1. Dimou L, Gallo V. NG2-glia and their functions in the central nervous system. Glia 2015, 63: 1429-1451.
2. Snaidero N, Möbius W, Czopka T, Hekking L, Mathisen C, Verkleij D, et al. Myelin membrane wrapping of CNS axons by $\mathrm{PI}(3,4,5) \mathrm{P} 3$-dependent polarized growth at the inner tongue. Cell 2014, 156: 277-290.

3. Taveggia C, Feltri M, Wrabetz L. Signals to promote myelin formation and repair. Nat Rev Neurol 2010, 6: 276-287.

4. Plemel J, Liu W, Yong V. Remyelination therapies: a new direction and challenge in multiple sclerosis. Nat Rev Drug Discov 2017, 16: 617-634.

5. Hagemeier K, Brück W, Kuhlmann T. Multiple sclerosis remyelination failure as a cause of disease progression. Histol Histopathol 2012, 27: 277-287.

6. Kuhlmann T, Miron V, Cui Q, Cuo Q, Wegner C, Antel J, et al. Differentiation block of oligodendroglial progenitor cells as a cause for remyelination failure in chronic multiple sclerosis. Brain 2008, 131: 1749-1758.

7. Brown SA, Neish AC. Shikimic acid as a precursor in lignin biosynthesis. Nature 1955, 175: 688-689.

8. Martínez J, Bolívar F, Escalante A. Shikimic acid production in Escherichia coli: from classical metabolic engineering strategies to omics applied to improve its production. Front Bioeng Biotechnol 2015, 3: 145.

9. Rabelo T, Zeidán-Chuliá F, Caregnato F, Schnorr C, Gasparotto $\mathrm{J}$, Serafini $\mathrm{M}$, et al. In vitro neuroprotective effect of shikimic acid against hydrogen peroxide-induced oxidative stress. J Mol Neurosci 2015, 56: 956-965.

10. Russell RJ, Haire LF, Stevens DJ, Collins PJ, Lin YP, Blackburn GM, et al. The structure of H5N1 avian influenza neuraminidase suggests new opportunities for drug design. Nature 2006, 443: 45.

11. Borah J. Shikimic acid: a highly prospective molecule in pharmaceutical industry. Curr Sci 2015, 109. https://doi.org/10. 18520/v109/i9/1672-1679.

12. Rabelo T, Guimarães A, Oliveira M, Gasparotto J, Serafini M, de Souza Araújo A, et al. Shikimic acid inhibits LPS-induced cellular pro-inflammatory cytokines and attenuates mechanical hyperalgesia in mice. Int Immunopharmacol 2016, 39: 97-105.

13. Huang F, Xiu Q, Sun J, Hong E. Anti-platelet and anti-thrombotic effects of triacetylshikimic acid in rats. J Cardiovasc Pharmacol 2002, 39: 262-270.

14. Elseedi HR, Ringbom T, Torssell K, Bohlin L. Constituents of Hypericum laricifolium and their cyclooxygenase (COX) enzyme activities. Chem Pharm Bull (Tokyo) 2003, 51: 1439-1440.

15. Sun D, Yu Z, Fang X, Liu M, Pu Y, Shao Q, et al. LncRNA GAS5 inhibits microglial M2 polarization and exacerbates demyelination. EMBO Rep 2017, 18: 1801-1816.

16. Luo F, Burke K, Kantor C, Miller R, Yang Y. Cyclin-dependent kinase 5 mediates adult OPC maturation and myelin repair through modulation of Akt and GsK-3 $\beta$ signaling. J Neurosci 2014, 34: 10415-10429.

17. Franklin R, Ffrench-Constant C. Remyelination in the CNS: from biology to therapy. Nat Rev Neurosci 2008, 9: 839-855.

18. Yu Z, Sun D, Feng J, Tan W, Fang X, Zhao M, et al. MSX3 switches microglia polarization and protects from inflammationinduced demyelination. J Neurosci 2015, 35: 6350-6365.

19. Li C, Xiao L, Liu X, Yang W, Shen W, Hu C, et al. A functional role of NMDA receptor in regulating the differentiation of oligodendrocyte precursor cells and remyelination. Glia 2013, 61: 732-749.

20. Xiao L, Guo D, Hu C, Shen W, Shan L, Li C, et al. Diosgenin promotes oligodendrocyte progenitor cell differentiation through estrogen receptor-mediated ERK1/2 activation to accelerate remyelination. Glia 2012, 60: 1037-1052.

21. Fang X, Sun D, Wang Z, Yu Z, Liu W, Pu Y, et al. MiR-30a positively regulates the inflammatory response of microglia in experimental autoimmune encephalomyelitis. Neurosci Bull 2017, 33: 603-615. 
22. Hoflich KM, Beyer C, Clarner T, Schmitz C, Nyamoya S, Kipp $\mathrm{M}$, et al. Acute axonal damage in three different murine models of multiple sclerosis: A comparative approach. Brain Res 2016, 1650: 125-133.

23. Ebner S, Dunbar M, McKinnon R. Distinct roles for PI3 K in proliferation and survival of oligodendrocyte progenitor cells. J Neurosci Res 2000, 62: 336-345.

24. Cui Q, Almazan G. IGF-I-induced oligodendrocyte progenitor proliferation requires PI3 K/Akt, MEK/ERK, and Src-like tyrosine kinases. J Neurochem 2007, 100: 1480-1493.

25. Imamura $\mathrm{O}$, Pagès $\mathrm{G}$, Pouysségur J, Endo $\mathrm{S}$, Takishima K. ERK1 and ERK2 are required for radial glial maintenance and cortical lamination. Genes Cells 2010, 15: 1072-1088.

26. Guardiola-Diaz H, Ishii A, Bansal R. Erk1/2 MAPK and mTOR signaling sequentially regulates progression through distinct stages of oligodendrocyte differentiation. Glia 2012, 60: 476-486.

27. Franklin R, Goldman S. Glia disease and repair-remyelination. Cold Spring Harb Perspect Biol 2015, 7: a020594.

28. Zawadzka M, Rivers L, Fancy S, Zhao C, Tripathi R, Jamen F, et al. CNS-resident glial progenitor/stem cells produce Schwann cells as well as oligodendrocytes during repair of CNS demyelination. Cell Stem Cell 2010, 6: 578-590.

29. Crawford A, Stockley J, Tripathi R, Richardson W, Franklin R. Oligodendrocyte progenitors: adult stem cells of the central nervous system? Exp Neurol 2014, 260: 50-55.

30. Hartley MD, Altowaijri G, Bourdette D. Remyelination and multiple sclerosis: therapeutic approaches and challenges. Curr Neurol Neurosci Rep 2014, 14: 1-9.

31. Keough M, Yong V. Remyelination therapy for multiple sclerosis. Neurotherapeutics 2013, 10: 44-54.

32. Hu J, He H, Yang Z, Zhu G, Kang L, Jing X, et al. Programmed death ligand-1 on microglia regulates Th1 differentiation via nitric oxide in experimental autoimmune encephalomyelitis. Neurosci Bull 2016, 32: 70-82.

33. Chang A, Tourtellotte W, Rudick R, Trapp B. Premyelinating oligodendrocytes in chronic lesions of multiple sclerosis. N Engl J Med 2002, 346: 165-173.

34. Tang L, Ye J, Jiang S, Zheng J. 3,4-oxo-isopropylidene-shikimic acid inhibits cerebral ischemia-induced oxidative stress and neuronal apoptosis in rats. Am J Transl Res 2017, 9: 1764-1773.
35. Constantinescu C, Farooqi N, O’Brien K, Gran B. Experimental autoimmune encephalomyelitis (EAE) as a model for multiple sclerosis (MS). Br J Pharmacol 2011, 164: 1079-1106.

36. Hall S. The effect of injections of lysophosphatidyl choline into white matter of the adult mouse spinal cord. J Cell Sci 1972, 10: $535-546$.

37. Gudi V, Gingele S, Skripuletz T, Stangel M. Glial response during cuprizone-induced de- and remyelination in the CNS: lessons learned. Front Cell Neurosci 2014, 8: 73.

38. Gonsalvez D, Ferner A, Peckham H, Murray S, Xiao J. The roles of extracellular related-kinases 1 and 2 signaling in CNS myelination. Neuropharmacology 2016, 110: 586-593.

39. Narayanan S, Flores A, Wang F, Macklin W. Akt signals through the mammalian target of rapamycin pathway to regulate CNS myelination. J Neurosci 2009, 29: 6860-6870.

40. Tyler W, Gangoli N, Gokina P, Kim H, Covey M, Levison S, et al. Activation of the mamalian target of rapamycin (mTOR) is essential for oligodendrocyte differentiation. J Neurosci 2009, 29: 6367-6378.

41. Ma XM, Blenis J. Molecular mechanisms of mTOR-mediated translational control. Nat Rev Mol Cell Biol 2009, 10: 307-318.

42. Mendoza MC, Er EE, Blenis J. The Ras-ERK and PI3 K-mTOR pathways: cross-talk and compensation. Trends Biochem Sci 2011, 36: 320-328.

43. McCubrey JA, Steelman LS, Chappell WH, Abrams SL, Franklin RA, Montalto G, et al. Ras/Raf/MEK/ERK and PI3 K/PTEN/ Akt/mTOR cascade inhibitors: how mutations can result in therapy resistance and how to overcome resistance. Oncotarget 2012, 3: 1068-1111.

44. Manna K, Khan A, Kr Das D, Bandhu Kesh S, Das U, Ghosh S, et al. Protective effect of coconut water concentrate and its active component shikimic acid against hydroperoxide mediated oxidative stress through suppression of NF-kappaB and activation of Nrf2 pathway. J Ethnopharmacol 2014, 155: 132-146.

45. Zhao C, Ma D, Zawadzka M, Fancy SP, Elis-Williams L, Bouvier G, et al. Sox2 sustains recruitment of oligodendrocyte progenitor cells following CNS demyelination and primes them for differentiation during remyelination. J Neurosci 2015, 35: 11482-11499.

46. Moll NM, Hong E, Fauveau M, Naruse M, Kerninon C, Tepavcevic V, et al. SOX17 is expressed in regenerating oligodendrocytes in experimental models of demyelination and in multiple sclerosis. Glia 2013, 61: 1659-1672. 